\title{
Prospective plasma lipid profiling in individuals with and without depression
}

\author{
Dietmar Enko ${ }^{1,2^{*}}$, Wolfgang Brandmayr ${ }^{3}$, Gabriele Halwachs-Baumann ${ }^{1}$, Wolfgang J. Schnedl ${ }^{4}$, \\ Andreas Meinitzer ${ }^{2}$ and Gernot Kriegshäuser ${ }^{1,2}$
}

\begin{abstract}
Background: So far, studies on possible association of plasma lipid levels and depressive disorder are contradictory. This prospective work aimed at assessing a plasma lipid profile in individuals with major depression and healthy controls.

Methods: In total, 94 patients with major depression and 152 healthy controls were included in this prospective study. After an overnight fasting state of $12 \mathrm{~h}$ they underwent blood drawing for triglyzerides (TG), total cholesterol, low-density lipoprotein (LDL)- and high-density lipoprotein (HDL)-cholesterol measurements. All participants were evaluated in a clinical interview and filled out the self-rating Beck Depression Inventory (BDI-II) scale to identify depressive symptomatology.

Results: Ninety-four patients with major depression showed significantly higher median (interquartile range) plasma TG levels (108.0 [75.8-154.1] vs. 84.0 [63.0-132.2] mg/dL, $P=0.014$ ) and significantly lower HDL-cholesterol levels (55.0 [46.9-123.0] vs. 61.5 [47.4-72.6] $\mathrm{mg} / \mathrm{dL}, P=0.049$ ) compared to 152 individuals without depression, respectively. Total and LDL-cholesterol concentrations were observed slightly higher in patients with major depression. Significant positive correlation was found between TG, total cholesterol and LDL-cholesterol concentrations and the BDI-II score $(p=0.027,0.048$ and 0.018$)$, and in tendency negative correlation between HDL-cholesterol levels and the BDI-II score $(P=0.091)$, respectively.

Conclusions: Depressive individuals were found with adverse plasma lipid patterns of higher TG and lower HDL-cholesterol levels compared to healthy controls. On this basis, the authors would suggest the implementation of routine lipid measurements in order to stratify these patients by their cardiovascular risk.
\end{abstract}

Keywords: Biomarkers, Cholesterol, Depression, Lipids, Triglycerides

\section{Background}

In the last years the interest in the relationship between plasma lipid composition and disease increased rapidly. In clinical routine, total cholesterol, low-density lipoprotein (LDL)- and high-density lipoprotein (HDL)-cholesterol, and triglycerides (TG) are used as basic lipid parameters to identify individuals at risk for cardiovascular disease.

Hyperlipidemia (i.e., hypercholesterinemia and/or hypertriglyceridemia) is a well-established risk factor

\footnotetext{
* Correspondence: dietmar.enko@gespag.at

${ }^{1}$ Institute of Clinical Chemistry and Laboratory Medicine, General Hospital

Steyr, Sierningerstraße 170, 4400 Steyr, Austria

${ }^{2}$ Clinical Institute of Medical and Chemical Laboratory Diagnostics, Medical

University of Graz, Auenbruggerplatz 15, 8036 Graz, Austria

Full list of author information is available at the end of the article
}

for cardiovascular disease [1]. In addition, depression must be considered as an independent risk factor for myocardial infarction and increased mortality in patients with coronary heart disease [2, 3]. However, well-documented predictive laboratory biomarkers of depression are still lacking, and the question raises, if depression might be associated with an altered plasma lipid pattern.

In the current literature, findings regarding a possible link between depression and blood lipid levels are contradictory. A number of previous studies have found an association between lower total cholesterol and depression [4-7]. Other reports indicate, that depression might be related to higher blood cholesterol levels [8-10]. Inconsistent findings were also obtained with the less

(C) The Author(s). 2018 Open Access This article is distributed under the terms of the Creative Commons Attribution 4.0 International License (http://creativecommons.org/licenses/by/4.0/), which permits unrestricted use, distribution, and 
extensively assessed LDL- and HDL-cholesterol, and TG $[6,7,11]$.

These mixed results reflect the complexity of possible associations between depressive disorders and lipid biomarkers. Discrepant findings, however, may be explained by a broad spectrum of different study designs and methodological variations (i.e., restricted age range, small sample size, heterogenous study populations) $[11,12]$. For this reason the comparability of studies and the generalizability of outcomes is limited [11].

In addition, previous reports not always considered TG levels in their study design $[5,10,12]$. This type of major circulating lipid is responsible for maintaining the body's energy balance and might also be involved in the development of cognitive impairment in individuals suffering from a depressive disorder [13].

To address the above mentioned limitations of previous reports, the present work was performed in a carefully evaluated homogenous psychiatric cohort with depression out of any other psychiatric comorbidities. This study aimed at investigating possible alterations of TG, total cholesterol, and LDL- and HDL-cholesterol plasma levels in a large sample of well-characterized patients including men and women over a broad age range sub-grouped by the presence or absence of major depression.

\section{Methods}

\section{Participants and study design}

A total of 246 participants aged between 18 and 70 years were recruited for this prospective study. The baseline characteristics of the study population are shown in Table 1. The average age was $40.5 \pm 14.8$ years. Eighty-eight (35.77\%) individuals were male and 158 (64.23\%) were female.

Out of these individuals, 94 suffered from a major depressive disorder without any other psychiatric comorbidity. They were diagnosed and treated by experienced psychiatrists at the Department of Psychiatry and Psychotherapeutic Medicine (General Hospital Steyr, Steyr, Austria). A total of 152 individuals with neither a depressive symptomatology nor a former history of psychiatric disorder, who visited the outpatient clinic of the Institute of Clinical Chemistry and Laboratory Medicine (General Hospital Steyr, Steyr, Austria) for a medical health check-up served as healthy controls. The gender and age groups of individuals with and without depression are presented in Table 2.

All study participants filled out the Beck Depression Inventory (BDI-II) questionnaire [14] and were investigated for the complete lipid status (i.e., TG, total cholesterol, LDL- and HDL-cholesterol). At study entry, none of the patients were under medication of lipid-lowering agents. Height $(\mathrm{cm})$ and weight $(\mathrm{kg})$ were measured with a wall-mounted metric tape and a calibrated personal scale to calculate the body mass index (BMI) $\left(\mathrm{kg} / \mathrm{m}^{2}\right)$.

\section{Blood collection and clinical laboratory procedures} Blood samples were drawn into VACUETTE LH lithium heparin tubes $(4 \mathrm{~mL})$ (Greiner Bio-one International $\mathrm{GmbH}$, Kremsmünster, Austria) after an overnight fasting state $(12 \mathrm{~h})$ in the morning between 08.00 and 10.00 . Samples were then centrifuged at $2000 \mathrm{x}$ g for $10 \mathrm{~min}$. All analyses were performed within one day after blood collection. Plasma TG (desirable level $\leq 150 \mathrm{mg} / \mathrm{dL}$ ), total cholesterol (desirable level $\leq 200 \quad \mathrm{mg} / \mathrm{dL}$ ), LDL-cholesterol (desirable level depends on cardiovascular risk) and HDL-cholesterol (desirable level $>40 \mathrm{mg}$ / $\mathrm{dL}$ ) were measured using commercial enzymatic methodology on a Dimension Vista 1500 System (Siemens Healthcare GmbH, Vienna, Austria).

\section{BDI-II}

The 21-question multiple-choice survey (scale: $0-3$ ) was used to measure the severity of depression. The total values of BDI-II range between 0 and 63 points [15].

Table 1 Baseline characteristics of all individuals included in this study $(n=246)$

\begin{tabular}{|c|c|c|c|c|c|}
\hline & Minimum & 1st quartile & Median & 3rd quartile & Maximum \\
\hline Age (years) & 18 & 27 & 39 & 52 & 70 \\
\hline Height (m) & 1.53 & 1.65 & 1.70 & 1.78 & 1.98 \\
\hline Weight (kg) & 20 & 60 & 71 & 83 & 142 \\
\hline BMI $\left(\mathrm{kg} / \mathrm{m}^{2}\right)$ & 7.35 & 21.47 & 24.14 & 27.73 & 49.13 \\
\hline Triglycerides (mg/dL) & 28 & 65 & 97 & 138 & 312 \\
\hline Total cholesterol (mg/dL) & 112 & 167 & 191 & 219.3 & 320 \\
\hline LDL cholesterol (mg/dL) & 50 & 94 & 116 & 145 & 228 \\
\hline HDL cholesterol (mg/dL) & 33 & 47 & 58 & 70.1 & 123 \\
\hline BDI-II score & 0 & 3 & 10 & 20 & 50 \\
\hline
\end{tabular}

Abbreviations: $B M I$ body mass index, $L D L$ low-density lipoprotein, $H D L$ high-density lipoprotein, $B D I-I /$ Beck depression inventory 
Table 2 Gender and age groups of individuals with and without depression

\begin{tabular}{llllllll}
\hline & \multicolumn{3}{l}{ Depression } & & & \multicolumn{3}{l}{ Non depression } \\
\cline { 1 - 2 } Age groups (years) & $\begin{array}{l}\text { Female } \\
(\mathrm{n})\end{array}$ & $\begin{array}{l}\text { Male } \\
(\mathrm{n})\end{array}$ & $\begin{array}{l}\text { Total } \\
(\mathrm{n})\end{array}$ & & $\begin{array}{l}\text { Female } \\
(\mathrm{n})\end{array}$ & $\begin{array}{l}\text { Male } \\
(\mathrm{n})\end{array}$ & $\begin{array}{l}\text { Total } \\
(\mathrm{n})\end{array}$ \\
\hline $18-99$ & 24 & 10 & 34 & & 32 & 10 & 42 \\
$30-49$ & 20 & 9 & 29 & & 37 & 29 & 66 \\
$50-70$ & 20 & 11 & 31 & & 25 & 19 & 44 \\
Total & 64 & 30 & 94 & & 94 & 58 & 152 \\
\hline
\end{tabular}

\section{Statistical analysis}

Descriptive statistics were performed to summarize and present the study parameters. The distribution of data was calculated with the Kolmogorov-Smirnov test. As the observed metric values were not normally distributed, the exact Mann-Whitney U-test was used for subgroup comparisons. Not normally distributed data were described as medians (Q1 - Q3). A P-value of $<0.05$ was considered statistically significant. For all calculations, the Analyse-it ${ }^{\bullet}$ software version 4.92 (Analyse-it Software, Ltd., Leeds, United Kingdom) was used.

\section{Results}

\section{Lipid measurements}

All in all, 53 (21.15\%) out of 246 subjects investigated here had plasma TG levels >150 mg/dL, and 104 (42.3\%) total cholesterol concentrations $>200 \mathrm{mg} / \mathrm{dL}$, respectively. The plasma lipid patterns obtained for all individual investigated here are shown in Table 3. Patients with major depressive disorder $(n=94)$ had significantly higher median (interquartile range) plasma TG levels (108.0 [75.8-154.1] mg/dL) compared to healthy controls $(n=152) \quad(84.0 \quad[63.0-132.2] \quad \mathrm{mg} / \mathrm{dL}) \quad(P=0.014)$. Moreover, HDL-cholesterol was significantly lowered (55.0 [46.9-123.0] mg/dL) in subjects with major depression compared to the healthy control group (61.5 [47.4$72.6] \mathrm{mg} / \mathrm{dL})(P=0.049)$. Total and LDL-cholesterol concentrations were observed slightly higher in patients with major depression. The box-and-whisker plots of the complete lipid status are illustrated in Fig. 1 (a-d).

Subgroup analysis of males and females and different age groups showed higher TG, total and LDL-cholesterol and lower HDL cholesterol plasma concentrations in patients with major depression compared to healthy controls in all groups. In females, individuals with major depression $(n=64)$ had significantly higher plasma TG (98.5 [66.8-133.5] mg/dL vs. 80.0 [61.8121.0] $\mathrm{mg} / \mathrm{dL}, \quad P=0.022)$ and significantly lower HDL-cholesterol levels (59.5 [49.0-70.6] mg/dL vs. 66.5 [55.8-76.1] $\mathrm{mg} / \mathrm{dL}, \quad P=0.036)$ compared to healthy controls $(n=94)$, whereas differences of plasma TG (117.5 [97.8-161.2] mg/dL vs. 104.5 [67.9-154.6] mg/dL, $P=0.243)$ and HDL-cholesterol concentrations (47.0 [42.9-54.2] mg/dL vs. 49.0 [42.0-64.1] mg/dL, $P=0.317$ ) were not significant between depressive $(n=30)$ and non-depressive males $(n=58)$, respectively (Table 2 ).

\section{Correlations between lipid parameters and severity of depressive symptoms}

There was a positive correlation between BDI-II score and TG $(P=0.027$, Pearson's correlation coefficient 0.141), total cholesterol $(P=0.048$, Pearson's correlation coefficient 0.126$)$, and LDL-cholesterol $(P=0.018$, Pearson's correlation coefficient 0.150 ), and in tendency a negative correlation with HDL-cholesterol $(P=0.091$, Pearson's correlation coefficient-0.108), respectively. HDL-cholesterol showed a highly inverse correlation with TG $(P<0.001$, Pearson's correlation coefficient 0.456).

\section{Discussion}

In the present study, 94 patients with major depressive disorder and 152 healthy controls were assessed and compared for TG, total cholesterol, LDL- and HDL-cholesterol. Individuals with depression were found to have significantly higher plasma TG (108.0 [75.8-154.1] vs. 84.0 [63.0 vs. 132.2$] \mathrm{mg} / \mathrm{dL}, P=0.014$ ) and lowered HDL-cholesterol levels (55.0 [46.9-123.0] vs. 61.5 [47.4 vs.

Table 3 Study parameters observed for 94 patients with major depression and 152 healthy controls

\begin{tabular}{llll}
\hline & Depressive patients & Healthy controls & $P$-value \\
\hline Height $(\mathrm{m})$ & $1.68(1.65-1.78)$ & $1.70(1.64-1.77)$ & 0.931 \\
Weight $(\mathrm{kg})$ & $74.5(60.0-90.0)$ & $70.0(60.0-80.6)$ & 0.214 \\
BMI $\left(\mathrm{kg} / \mathrm{m}^{2}\right)$ & $25.11(21.36-28.50)$ & $23.95(21.53-26.43)$ & 0.134 \\
Triglycerides $(\mathrm{mg} / \mathrm{dL})$ & $108.0(75.8-154.1)$ & $84.0(63.0-132.2)$ & 0.014 \\
Total cholesterol $(\mathrm{mg} / \mathrm{dL})$ & $192.5(166.0-225.2)$ & $190.0(168.0-218.0)$ & 0.529 \\
LDL cholesterol $(\mathrm{mg} / \mathrm{dL})$ & $120.0(93.8-152.0)$ & $114.0(94.0-140.0)$ & 0.269 \\
HDL cholesterol $(\mathrm{mg} / \mathrm{dL})$ & $55.0(46.9-123.0)$ & $61.5(47.4-72.6)$ & 0.049 \\
BD-II score & $25(18-33)$ & $5(2-9)$ & $<0.001$ \\
\hline
\end{tabular}

Abbreviations: $B M I$ body mass index, $L D L$ low-density lipoprotein, $H D L$ high-density lipoprotein, $B D I-I /$ Beck depression inventory Data are presented as medians (Q1 - Q3) 

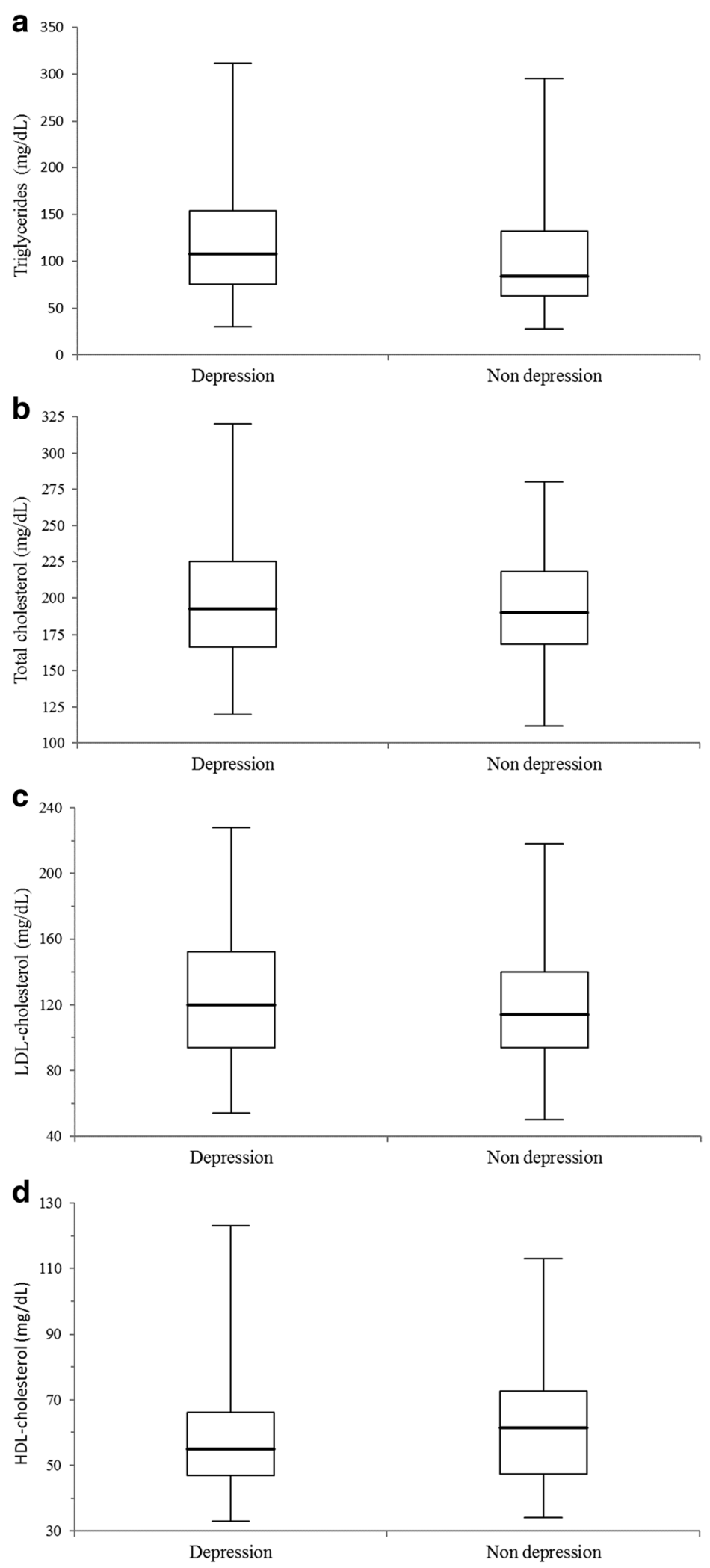

Fig. 1 Box-and-whisker plots of a TG, b total cholesterol, c LDL-cholesterol, and $\mathbf{d}$ HDL-cholesterol plasma level comparisons between 94 patients with major depression and 152 healthy controls ( $P$-values were $0.014,0.529,0.269$, and 0.049 ). The central boxes represent the 25 th to 75 th percentile range. The lines inside the boxes show the median value for each group 
$72.6] \mathrm{mg} / \mathrm{dL}, P=0.049)$ compared to healthy subjects. Total and LDL-cholesterol measurements were observed slightly higher in individuals with depression. These findings are in agreement with two recently published studies that found higher levels of TG, total and LDL-cholesterol and lower HDL-cholesterol levels in individuals with depressive disorder versus healthy controls $[8,16]$.

In contrast, a previous study by Aijänseppä et al. reported concordant TG concentrations and lower total and LDL-cholesterol measurements in subjects with depression as compared to individuals without depression [17]. One recently published work reported higher TG and also higher HDL-cholesterol levels in depressive individuals [18]. Study design variations and heterogeneity of study participants are possible explanations for these inconsistent findings. While the present study investigated 246 individuals (female: 158) with a mean age of 40.5 years, Aijänseppä et al. studied 421 men with a mean age of 76.8 years. A clear advantage of our study was the approach of a carefully evaluated homogenous psychiatric cohort with depression out of any other psychiatric comorbidities.

Herein, individuals suffering from major depression were observed with significantly elevated TG levels which also positively correlated with disease severity. One previous Finnish longitudinal study, determining serum lipid level patterns (i.e., TG, LDL- and HDL-cholesterol) and depressive symptoms during childhood and early adulthood, indicated, that rapid increases of TG at early age were predictive of depression onset [19]. However, the investigators failed to demonstrate an association between any LDL- or HDL-cholesterol pattern change and depressive symptoms [19].

Adverse lipid patterns in depressive disorder are associated with life-style related factors. Individuals with depression were reported to eat more often foods high in energy density compared to healthy controls [20]. This cofactor might be one possible reason for positive associations between plasma lipid levels and depression found in this study.

Recently, elevated TG levels and depression severity were shown to play a major role in the development of cardio-metabolic disease [21]. Depression is known to be associated with an increased activity of the sympathetic nervous system and the hypothalamic-pituitary-adrenal cortex axis $[20,22]$. Cortisol increases serum levels of circulating free fatty acids $[20,23]$, which in turn stimulate the very-low density lipoprotein (VLDL) synthesis in the liver resulting in elevated TG concentrations [20].

Present data showed, that in subjects with major depression significantly elevated TG levels coincided with significantly lowered HDL-cholesterol in a highly inverse correlated manner $(P<0.001, \quad$ Pearson's correlation coefficient - 0.456). A previous study found this adverse lipid pattern associated with an increased risk of recurrent or chronic depression [24]. Moreover, recent evidence suggests that elevated TG levels associated with lowered HDL-cholesterol predispose to atherosclerosis [24-26]. Raised TG are indicative of high remnant cholesterol concentrations, leading to intimal low-grade inflammation and accumulation of foam cells and atherosclerotic plaques [25]. Regarding the findings of this study, TG and HDL-cholesterol measurements may have the potential to serve as screening biomarkers in individuals with depression thereby contributing to the preservation of long-term cardiovascular health.

The major limitation of this cross-sectional study is that cortisol measurements and lifestyle-related factors such as dietary habits, alcohol use or smoking behaviour were not taken into account. Furthermore, we cannot rule out the influence of antidepressant medication on the patients' lipid metabolism. However, prospective longitudinal studies including follow-up measurements of blood lipid levels are warranted to fully elucidate the associations with depressive disorders.

\section{Conclusions}

Individuals with depressive disorder showed higher TG, total and LDL-cholesterol and lower HDL-cholesterol plasma levels compared to healthy controls. On this basis, the authors would suggest the implementation of routine blood lipid measurements in order to stratify these patients by their cardiovascular risk.

\section{Abbreviations}

BDI-II: Beck Depression Inventory; BMI: body mass index; HDL: high-density lipoprotein; LDL: Iow-density lipoprotein; TG: triglycerides; VLDL: very-low density lipoprotein

\section{Funding}

The authors received no financial support for the research, authorship, and/ or publication of this article.

\section{Availability of data and materials \\ The datasets used and/or analyzed during the current study are available from the corresponding author upon reasonable request.}

\section{Authors' contributions \\ DE, GHB, WJS, AM, and GK were responsible for the study concept and design. DE, AM and GK collected, analyzed and interpreted the data. DE wrote the first draft of the manuscript. GK revised the manuscript critically and all the other authors finally read and approved the last version of this manuscript.}

Ethics approval and consent to participate

This study was approved by the Ethical Committee of the Johannes Kepler University Linz (Linz, Austria) and carried out according to the Declaration of Helsinki. All study participants gave their written informed consent.

Competing interests

The authors declare that they have no competing interests. 


\section{Publisher's Note}

Springer Nature remains neutral with regard to jurisdictional claims in published maps and institutional affiliations.

\section{Author details}

'Institute of Clinical Chemistry and Laboratory Medicine, General Hospital Steyr, Sierningerstraße 170, 4400 Steyr, Austria. ${ }^{2}$ Clinical Institute of Medical and Chemical Laboratory Diagnostics, Medical University of Graz, Auenbruggerplatz 15, 8036 Graz, Austria. ${ }^{3}$ Department of Psychiatry and Psychotherapeutic Medicine, General Hospital Steyr, Sierningerstraße 170, 4400 Steyr, Austria. ${ }^{4}$ Practice for General Internal Medicine, Dr.

Theodor-Körner-Straße 19b, 8600 Bruck/Mur, Austria.

Received: 4 April 2018 Accepted: 5 June 2018

Published online: 26 June 2018

\section{References}

1. Nelson RH. Hyperlipidemia as a risk factor for cardiovascular disease. Prim Care. 2013:40:195-211.

2. Sauer WH, Berlin JA, Kimmel SE. Selective serotonin reuptake inhibitors and myocardial infarction. Circulation. 2001;104:1894-8.

3. Barth J, Schumacher M, Herrmann-Lingen C. Depression as a risk factor for mortality in patients with coronary heart disease: a meta-analysis. Psychosom Med. 2004;66:802-13.

4. Ong KL, Morris MJ, McClelland RL, Maniam J, Allison MA, Rye KA. Lipids, lipoprotein distribution and depressive symptoms: the multi-ethnic study of atherosclerosis. Transl Psychiatry. 2016;6:e692.

5. Tedders SH, Fokong KD, McKenzie LE, Wesely C, Yu L, Zhang J. Low cholesterol is associated with depression among US household population. J Affect Disord. 2011;135:115-21.

6. Maes M, Smith R, Christophe A, Vandoolaeghe E, Van Gastel A, Neels H, Demedts $P$, Wauters A, Meltzer HY. Lower serum high-density lipoprotein cholesterol (HDL-C) in major depression and in depressed men with serious suicidal attempts: relationship with immune-inflammatory markers. Acta Psychiatr Scand. 1997;95:212-21.

7. Olusi SO, Fido AA. Serum lipid concentrations in patients with major depressive disorder. Biol Psychiatry. 1996:40:1128-31.

8. Moreira FP, Jansen K, Cardoso TA, Mondin TC, Magalhães PVDS, Kapczinski F, Souza LDM, da Silva RA, Oses JP, Wiener CD. Metabolic syndrome in subjects with bipolar disorder and major depressive disorder in a current depressive episode: population-based study. Metabolic syndrome in current depressive episode J Psychiatr Res. 2017;92:119-23.

9. Nakao M, Yano E. Relationship between major depression and high serum cholesterol in Japanese men. Tohoku J Exp Med. 2004;204:273-87.

10. Ledochowski M, Murr C, Sperner-Unterweger B, Neurauter G, Fuchs D. Association between increased serum cholesterol and signs of depressive mood. Clin Chem Lab Med. 2003:41:821-4.

11. van Reedt Dortland AK, Giltay EJ, van Veen T, van Pelt J, Zitman FG, Penninx BW. Associations between serum lipids and major depressive disorder: results from the Netherlands study of depression and anxiety (NESDA). J Clin Psychiatry. 2010;71:729-36

12. Beydoun MA, Beydoun HA, Dore GA, Fanelli-Kuczmarski MT, Evans MK, Zonderman AB. Total serum cholesterol, atherogenic indices and their longitudinal association with depressive symptoms among US adults. Transl Psychiatry. 2015;5:e518.

13. Shao $T N$, Yin $G Z$, Yin $X L$, Wu JQ, Du XD, Zhu HL, Liu JH, Wang XQ, Xu DW, Tang WJ, Hui L. Elevated triglyceride levels are associated with cognitive impairments among patients with major depressive disorder. Compr Psychiatry. 2017;75:103-9.

14. Steer RA, Ball R, Ranieri WF, Beck AT. Dimensions of the Beck depression inventory-II in clinically depressed outpatients. J Clin Psychol. 1999;55: $117-28$.

15. Beck AT, Steer RA, Brown GK. Manual for the Beck depression inventory-ll. San Antonio, TX: Psychological Corporation; 1996.

16. Nunes SO, Piccoli de Melo LG, Pizzo de Castro MR, Barboso DS, Vargas HO Berk M, Maes M. Atherogenic index of plasma and atherogenic coefficient are increased in major depression and bipolar disorder, especially when comorbid with tobacco use disorder. J Affect Disord. 2015;172:55-62.

17. Aijänseppä S, Kivinen P, Helkala EL, Kivelä SL, Tuomilehto J, Nissinen A. Serum cholesterol and depressive symptoms in elderly Finnish men. Int J Geriatr Psychiatry. 2002;17:629-34
18. Oh J, Kim TS. Serum lipid levels in depression and suicidality: the Korea National Health and nutrition examination survey (KNHANES) 2014. J Affect Disord. 2017;213:51-8.

19. Elovainio M, Pulkki-Råback L, Kivimäki M, Jokela M, Viikari J, Raitakari OT، Telama R, Keltikangas-Järvinen L. Lipid trajectories as predictors of depressive symptoms: the young Finns study. Health Psychol. 2010;29: 237-45.

20. Atlantis E, Lange K, Goldney RD, Martin S, Haren MT, Taylor A, O'Loughlin PD, Marshall V, Tilley W, Wittert GA. Specific medical conditions associated with clinically depressive symptoms in men. Soc Psychiatry Psychiatr Epidemiol. 2011:46:1303-12.

21. Lemche AV, Chaban OS, Lemche E. Depression contributing to dyslipidemic cardiovascular risk in the metabolic syndrome. J Endocrinol Investig. 2017; 40:539-46.

22. Goldston K, Baillie AJ. Depression and coronary heart disease: a review of the epidemiological evidence, explanatory mechanisms and management approaches. Clin Psychol Rev. 2008;28:288-306.

23. Xu C, He J, Jiang H, Zu L, Zhai W, Pu S, Xu G. Direct effect of glucocorticoids on lipolysis in adipocytes. Mol Endocrinol. 2009;23:1161-70.

24. Virtanen M, Ferrie JE, Akbaraly T, Tabak A, Jokela M, Ebmeier KP, SinghManoux A, Kivimäki M. Metabolic syndrome and symptom resolution in depression: a 5-year follow-up of older adults. J Clin Psychiatry. 2017; 78:e1-7.

25. Nordestgaard BG, Varbo A. Triglycerides and cardiovascular disease. Lancet. 2014;384:626-35.

26. Welty FK. How do elevated triglycerides and low HDL-cholesterol affect inflammation and atherothrombosis? Curr Cardiol Rep. 2013;15:400.

\section{Ready to submit your research? Choose BMC and benefit from:}

- fast, convenient online submission

- thorough peer review by experienced researchers in your field

- rapid publication on acceptance

- support for research data, including large and complex data types

- gold Open Access which fosters wider collaboration and increased citations

- maximum visibility for your research: over $100 \mathrm{M}$ website views per year

At BMC, research is always in progress.

Learn more biomedcentral.com/submissions 